\title{
Classical and reverse substituent effects in meta- and para-substituted nitrobenzene derivatives
}

\author{
Halina Szatylowicz $^{1}$ (D) Anna Jezuita $^{2} \cdot$ Krzysztof Ejsmont $^{2} \cdot$ Tadeusz M. Krygowski $^{3}$
}

Received: 8 November 2016 / Accepted: 25 January 2017 / Published online: 8 February 2017

(C) The Author(s) 2017. This article is published with open access at Springerlink.com

\begin{abstract}
Electron-accepting properties of the nitro group were studied in a series of meta- and para-X-substituted nitrobenzene derivatives $\left(\mathrm{X}=\mathrm{NMe}_{2}, \mathrm{NH}_{2}, \mathrm{OH}, \mathrm{OMe}, \mathrm{CH}_{3}, \mathrm{H}\right.$, $\mathrm{F}, \mathrm{Cl}, \mathrm{CF}_{3}, \mathrm{CN}, \mathrm{CHO}, \mathrm{COMe}, \mathrm{CONH}_{2}, \mathrm{COOH}, \mathrm{COCl}, \mathrm{NO}_{2}$, $\mathrm{NO})$. For this purpose Hammett-like approaches were applied based on quantum chemistry modeling; the B3LYP/6-311++ $\mathrm{G}(\mathrm{d}, \mathrm{p})$ method was used. The substituent effect (SE) was characterized by the mutually interrelated descriptors: the charge of the substituent active region, cSAR(X), and substituent effect stabilization energy, SESE, as well as substituent constants, $\sigma$. Classical SE is realized by dependences of the structural parameters of the nitro group (ONO angle and $\mathrm{NO}$ bond lengths) and cSAR $\left(\mathrm{NO}_{2}\right)$ on the above mentioned SE descriptors. The reverse substituent effect was clearly documented by a comparison of $\operatorname{cSAR}(\mathrm{X})$ values for monosubstituted benzenes, meta- and para-substituted nitrobenzenes as well as, additionally, for meta- and para-X-substituted anilines. For para-substituted systems the electron-accepting ability of the nitro group increases from cSAR $\left(\mathrm{NO}_{2}\right)=-0.170$ up to -0.284 in dinitrobenzene and nitroaniline, respectively.
\end{abstract}

Electronic supplementary material The online version of this article (doi:10.1007/s11224-017-0922-2) contains supplementary material, which is available to authorized users.

Halina Szatylowicz

halina@ch.pw.edu.pl

1 Faculty of Chemistry, Warsaw University of Technology, Noakowskiego 3, 00-664 Warsaw, Poland

2 Faculty of Chemistry, Opole University, Oleska 48, 45-052 Opole, Poland

3 Faculty of Chemistry, University of Warsaw, Pasteura 1, 02-093 Warsaw, Poland
Keywords Substituent effects · Electronic structure · Molecular modeling - Substituent effect stabilization energy · Charge of the substituent active region

\section{Introduction}

The nitro group belongs to one of the most electron accepting (EA) substituents and hence it attains an unusual interest as a substituent or a functional group. Firstly, the nitro group is very electronegative (the group electronegativity in the Pauling scale, $\chi_{\mathrm{NO} 2}$, is equal to 4.00 for a coplanar and 4.19 for a perpendicular orientation with respect to the benzene ring) [1] and as a consequence its strongly inductive effect influences the rest of the substituted molecule. Secondly, this group exhibits a great range of variability of its EA properties [2,3] with $\sigma_{\mathrm{p}}=0.78$ and $\sigma_{\mathrm{p}}{ }^{-}=1.27$ which dramatically depends on the kind of a moiety to which the group is attached [4]. A similar situation is with the resonance and field substituent constants $\sigma_{\mathrm{R}}$ and $\sigma_{\mathrm{F}}$ equal to 0.16 and 0.62 , respectively [3]. The inductive substituent constant [5], $\sigma_{\mathrm{I}}$, estimated from acid-base equilibrium constants of substituted acetic acids equals to 0.76. A rotation of $\mathrm{NO}_{2}$ group around $\mathrm{CN}$ bond changes $\sigma_{\mathrm{p}}{ }^{-}$values from 1.27 for a coplanar conformation to 0.70 for the perpendicular one [6], and so the latter is very close to the value to the field parameter [3].

Two comments should be made here. It has to be pointed out, according to a critical compilation by Exner (Table 10.2 in Ref. [2]), that the above mentioned SE characteristics are not the only ones, moreover, they sometimes differ up to 10-20\%. A good illustration can be given by the values of $\sigma_{\mathrm{p}}$ substituent constant for $\mathrm{NO}_{2}$ group ranging from 0.73 to 0.82 [2]. These deviations are 
mostly due to either some experimental errors or/and not exactly equivalent reference series, i.e. the intramolecular interactions responsible for the SE have slightly different mechanisms including also medium effects. Additionally, a substituent constant (SC) may depend on the aim of its application. For this purpose either a position of the substituent (e.g. meta- or para-) or, in other cases, the reaction site with strong ED (electron donating) or EA properties is chosen. A good example is a reference reaction for $\sigma_{\mathrm{p}}{ }^{-}$based on the acid-base equilibrium constants of phenol derivatives. In this case the reaction site is the hydroxy group which is a strongly ED functional group. Hence, e.g. for EA substituents in the para- position the appropriate substituent constants are significantly greater than the "classical" Hammett constants based on benzoic acid dissociation.

Undoubtedly, values of SCs depend on the kind of the moiety to which substituents are linked and depend on the selected reference reaction. Therefore, it seems to be valuable to undertake the studies of interrelation between the electron properties of the fixed functional group ("reaction site") $\mathrm{Y}$ and the ED or EA properties of the varying substituents $\mathrm{X}$ in a general reaction series $\mathrm{X}-\mathrm{R}-\mathrm{Y}$, where $\mathrm{R}$ is a transmitting moiety. The dependence of the properties for a given substituent $X$ on the kind of R-Y was named the reverse substituent effect [4], since this works in an opposite direction than the classical SE. In the latter substituents affect properties of $\mathrm{Y}$, whereas in the reverse $\mathbf{S E}$ various reaction sites cause changes in ED/EA properties of the substituents. This kind of intramolecular interactions is a subject of this paper.

The nitro group is of great significance due to wide applications of nitro-compounds which are very important chemicals, medicines [7], explosives [8, 9] or fertilizers [10]. So it is not surprising a great number of crystal structures deposited in the Cambridge Structural Database [11] (CSD) amounting over 38,000 records, as it has been noted recently [12].

Given such a great interest devoted to compounds with the nitro group it seems to be very advantageous to investigate an impact of the "fixed" nitro group on the properties of substituents X. Additionally, it is very important to use methods which allow to estimate their electron properties independently of reference reactions which rarely can be formulated for any molecular systems containing the nitro group. At present, several known substituent constants are mostly intuitively applied. The aim of this study is to verify the role of the nitro group on electron properties of substituents. For this purpose both the classical and reverse SE are examined for series of meta- and para-X-substituted nitrobenzene derivatives (Scheme 1) with 16 substituents $\left(\mathrm{X}=\mathrm{NMe}_{2}, \mathrm{NH}_{2}, \mathrm{OH}\right.$, $\mathrm{OMe}, \mathrm{CH}_{3}, \mathrm{H}, \mathrm{F}, \mathrm{Cl}, \mathrm{CF}_{3}, \mathrm{CN}, \mathrm{CHO}, \mathrm{COMe}, \mathrm{CONH}_{2}$, $\mathrm{COOH}, \mathrm{COCl}, \mathrm{NO}_{2}, \mathrm{NO}$ ).
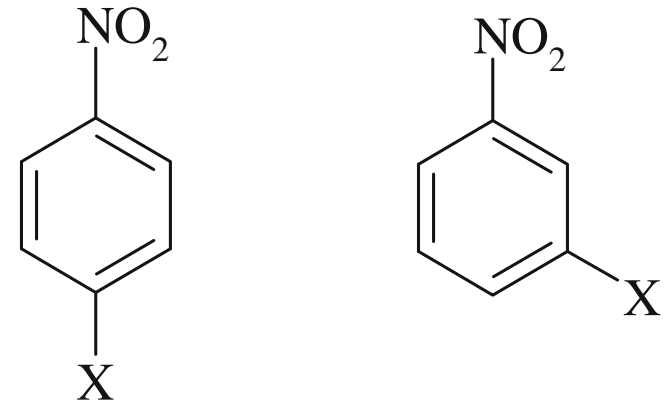

Scheme 1 General scheme of studied disubstituted benzene derivatives; $\mathrm{X}=\mathrm{NMe}_{2}, \mathrm{NH}_{2}, \mathrm{OH}, \mathrm{OMe}, \mathrm{CH}_{3}, \mathrm{H}, \mathrm{F}, \mathrm{Cl}, \mathrm{CF}_{3}, \mathrm{CN}, \mathrm{CHO}, \mathrm{COMe}$, $\mathrm{CONH}_{2}, \mathrm{COOH}, \mathrm{COCl}, \mathrm{NO}_{2}, \mathrm{NO}$

\section{Methodology}

For all studied structures an optimization without any symmetry constraints was performed with the use of the Gaussian09 program [13]. Three different methods (HF [14], DFT with B3LYP [15, 16] and M06-2X [17] functionals, and MP2 [18]) and three basis sets $\left(6-31+\mathrm{G}^{* *}, 6-311++\mathrm{G}^{* *}[19]\right.$ and aug-cc-pVDZ [20]) were applied for para- and meta-Xsubstituted nitrobenzenes to select the best one for the studied problem. To confirm that calculated structures correspond to the minima on the potential energy surface the vibrational frequencies were calculated at the same level of theory.

Similarly to the case of substituted anilines [21], considering the accuracy, sensitivity and computational costs, the B3LYP/ $6-311++\mathrm{G}^{* *}$ method was chosen for all further calculations. The choice was based on the energetic characteristic of the SE Substituent Effect Stabilization Energy (SESE) and on the comparison of the calculated values with those obtained using MP2/6-311++G** approach (see Table S1 in SI).

Various methods of charge partitioning (NBO [22], AIM [23] and Hirshfeld [24] charges) were used to obtain cSAR values. Natural Bond Orbital (NBO) charges and Hirshfeld's charges were computed in Gaussian program (with the use of NBO 6.0 module [25]). Bader's AIM atomic charges were performed using AIMAll program [26]. In this study only NBO charges were used owing to the good correlation between $\operatorname{cSAR}(\mathrm{X})$ values. All calculated $\mathrm{cSAR}$ values are shown in Table S2 (SI).

Properties of the substituents were characterized by substituent constants $(\sigma)$, SESE and $\operatorname{cSAR}(X)$ descriptors.

Substituent Effect Stabilization Energy, SESE, was estimated using a homodesmotic reaction [27-30].

$\mathrm{X}-\mathrm{R}-\mathrm{Y}+\mathrm{R} \rightarrow \mathrm{R}-\mathrm{X}+\mathrm{R}-\mathrm{Y}$

for which

$\mathrm{SESE}=\mathrm{E}(\mathrm{R}-\mathrm{X})+\mathrm{E}(\mathrm{R}-\mathrm{Y})-\mathrm{E}(\mathrm{X}-\mathrm{R}-\mathrm{Y})-\mathrm{E}(\mathrm{R})$

SESE values describe the energetic effect of the interaction between substituent $\mathrm{X}$ and the reaction site $\mathrm{Y}$, while $\mathrm{R}$ is 
treated as the transmitting moiety. In our study, $\mathrm{Y}$ is the nitro group $\left(\mathrm{NO}_{2}\right)$ while $\mathrm{R}$ denotes the benzene ring. The greater value of SESE (eq. 1) denotes the higher stabilization energy caused by the substituent effect.

Charge of the Substituent Active Region [31, 32], $\operatorname{cSAR}(\mathrm{X})$, is defined as a sum of total charges at all atoms of the substituent $\mathrm{X}$ and the charge at the ipso carbon atom.

$\operatorname{cSAR}(\mathrm{X})=q(\mathrm{X})+q\left(\mathrm{C}_{\mathrm{ipso}}\right)$

The nitro group was characterized both by structural $\left(d_{\mathrm{CN}}\right.$, $d_{\mathrm{NO}}$ and a valence angle ONO, $\varphi$, see Fig. 1) and electronic $\left[\mathrm{cSAR}\left(\mathrm{NO}_{2}\right)\right]$ parameters.

\section{Results and discussion}

The substituent effect in meta- and para-substituted nitrobenzene derivatives may be considered by means of three ways of understanding this term. Firstly, as a classical description of the changes in properties observed in the nitro group due to the impact of the substituent (classical SE). Secondly, showing mutual dependences between structural and electronic parameters of the $\mathrm{NO}_{2}$ group resulted from the SE. Finally, as the reverse $\mathrm{SE}$ describing changes in $\mathrm{EA} / \mathrm{ED}$ properties of the substituent resulting from properties of the remainder of the molecule to which it is attached. Subsequent parts of this section are devoted to these issues.

Nevertheless, before going into detailed studies of SEs in meta- and para-substituted nitrobenzene derivatives by use of classical substituent constants $(\sigma)$ and quantum chemistry based cSAR(X) [31-33] and SESE [29, 30] characteristics we should determine their mutual interrelations.

The results in Table 1 and Fig. 2 reveal an excellent correlation between SESE and substituent constants for all three cases: for meta- and para-derivatives as well as for a joint approach the regression lines with $R^{2}>0.933$ are observed. Another two relationships presented by regressions in the

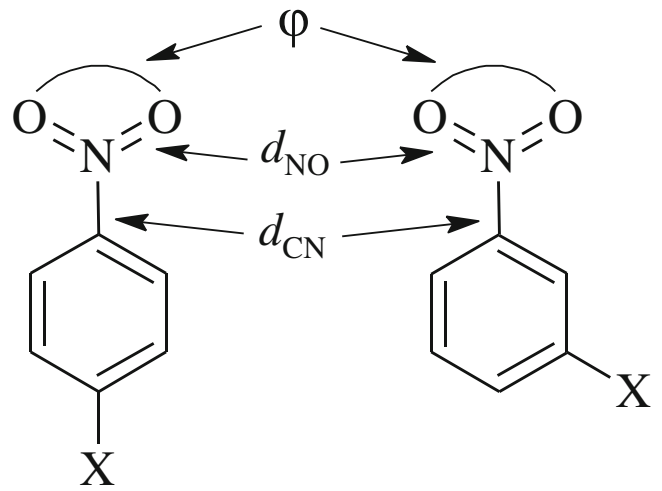

Fig. 1 Structural parameters $\left(d_{\mathrm{CN}}, d_{\mathrm{NO}}\right.$ and a valence angle $\left.\mathrm{ONO}, \varphi\right)$ of the reaction site
Table 1 are also acceptable, but similarly as in the case of aniline derivatives [21] the precision of regressions for metaseries is always lower than for the para-ones. However, in all three cases slopes, as the absolute values, are greater for metaderivatives than for para-systems. This is opposite to those observed for substituted aniline derivatives [21]. A greater sensitivity to the SE from the meta-position might be considered as a result of the property of the nitro group as metadirecting in the electrophilic substitution. Another possible interpretation could be associated with through space interactions between $\mathrm{NO}_{2}$ group and substituents, which in metapositions are closer to each other than in the para-one.

The best precision of the linear regression between SESE and classical substituent constants is understandable taking into account that both these SE characteristics include all effects of intramolecular interaction between substituents and the fixed group, $\mathrm{NO}_{2}$ this case. Both $\operatorname{cSAR}(\mathrm{X})$ and cSAR $\left(\mathrm{NO}_{2}\right)$ represent local changes in the electron structure and hence describe a slightly different situation.

\section{Classical substituent effect observed in $\mathrm{NO}_{2}$ group and its structural units}

The classical way of the SE interpretation is based on relating properties of the reaction site $(\mathrm{Y})$ to the substituent constants, $\sigma(\mathrm{X})$, in the general scheme X-R-Y. In this work, apart from $\sigma$ constants other descriptors of the SE are used, such as SESE and $\operatorname{cSAR}(\mathrm{X})$. In the case of the reaction site $\left(\mathrm{Y}=\mathrm{NO}_{2}\right)$ the properties taken into consideration are its electronic characteristic by $\operatorname{cSAR}\left(\mathrm{NO}_{2}\right)$ and structural unit parameters: $\mathrm{ONO}$ angle $(\varphi)$, NO bond lengths $\left(d_{\mathrm{NO}}\right)$ as well as the length of the linking $\mathrm{CN}$ bond $\left(d_{\mathrm{CN}}\right)$; each of them are subject of the SE from meta- and para-positions. All statistical data for this kind of interactions are given in Table 2.

As already mentioned, each of three structural parameters $\left(d_{\mathrm{NO}}, \varphi\right.$ and $\left.d_{\mathrm{CN}}\right)$ is important for the characterization of the nitro group and its interaction with the ring because they describe the nature of the link between $\mathrm{NO}_{2}$ group and the ring. Changes for the first two structural characteristics are very well described by the Hammett constants and SESE but worse by $\operatorname{cSAR}(\mathrm{X})$ as presented in Table 2 and illustrated in Figs S1S4 (in SI).

It is worth to note that the sensibility of $d_{\mathrm{NO}}$ on the $\mathrm{SE}$ is again stronger for para- than for meta-derivatives, contrary to the relation of $\varphi$ vs. $\sigma$ presented in Fig. S4. The latter may be associated with the property of the carbon atom in the metaposition which is reactive for the electrophilic substitution. What is more, if both series are considered together the obtained relations are characterized by $R^{2}>0.903$. In other words, it can be said that the variability of these parameters seems to be not dependent on the positions of the substituents.

Oppositely to the very good descriptions of $d_{\mathrm{NO}}$ and $\varphi$ angle by $\sigma$ constants the length of the linking bond $d_{\mathrm{CN}}$ does 
Table 1 Statistics of mutual correlations between substituent constants $(\sigma), \operatorname{cSAR}(\mathrm{X})$ and SESE: the equation $f(x)=a \cdot x+b$; $\Delta 1$ and $\Delta 2$ denote $f(x)$ and $x$ ranges of variability, respectively

\begin{tabular}{|c|c|c|c|c|c|c|c|c|}
\hline & $R^{2}$ & $a$ & $b$ & $a_{\mathrm{p}} / a_{\mathrm{m}}$ & $\Delta 1$ & $\Delta 1_{\mathrm{p}} / \Delta 1_{\mathrm{m}}$ & $\Delta 2$ & $\Delta 2_{\mathrm{p}} / \Delta 2_{\mathrm{m}}$ \\
\hline \multicolumn{9}{|c|}{$\mathrm{SESE}=a \cdot \sigma+b \mathrm{SESE} \sigma$} \\
\hline$m$ & 0.933 & -5.962 & 0.361 & \multirow[t]{3}{*}{0.79} & 5.55 & \multirow[t]{3}{*}{1.48} & 0.87 & \multirow[t]{3}{*}{2} \\
\hline$p$ & 0.975 & -4.686 & 0.030 & & 8.24 & & 1.74 & \\
\hline$m+p$ & 0.952 & -4.959 & 0.081 & & & & & \\
\hline \multicolumn{9}{|c|}{$\operatorname{cSAR}(\mathrm{X})=a \cdot \sigma+b \operatorname{cSAR}(\mathrm{X}) \sigma$} \\
\hline$m$ & 0.726 & -0.413 & 0.089 & \multirow[t]{2}{*}{0.63} & 0.356 & \multirow[t]{2}{*}{1.11} & 0.87 & \multirow[t]{2}{*}{2} \\
\hline$p$ & 0.919 & -0.259 & 0.039 & & 0.394 & & 1.74 & \\
\hline$m+p$ & 0.794 & -0.292 & 0.046 & & & & & \\
\hline \multicolumn{9}{|c|}{$\operatorname{cSAR}(\mathrm{X})=a \cdot \operatorname{SESE}+b \operatorname{cSAR}(\mathrm{X}) \mathrm{SESE}$} \\
\hline$m$ & 0.729 & 0.067 & 0.053 & \multirow[t]{2}{*}{0.81} & 0.356 & \multirow[t]{2}{*}{1.11} & 5.55 & \multirow[t]{2}{*}{1.48} \\
\hline$p$ & 0.913 & 0.054 & 0.037 & & 0.394 & & 8.24 & \\
\hline$m+p$ & 0.820 & 0.058 & 0.041 & & & & & \\
\hline
\end{tabular}

not give so clear dependence. It is important to note that variations in the $\mathrm{CN}$ bond length may serve as an indicator of changes in the resonance effect of the substituted nitrobenzene derivatives for electron donating substituents [34]. This is associated with an appearance of a contribution of the quinoidlike structure in the description of the electron system of the ring. The changes of $d_{\mathrm{CN}}$ on $\sigma$ constants are presented in Fig. S5. The obtained result is very significant. The slopes and the precision of regression lines for meta- and parasubstituted series differ dramatically. The para-series has a much higher slope than the meta-one $(0.017$ vs. 0.004$)$ and this is an important observation despite of the low precision of the regression line in the meta-series. It indicates a much smaller role of the quinoid structure for meta-substituted nitrobenzene derivatives than for the para-ones. This is also supported by the variation range of $d_{\mathrm{CN}}$ values for meta- and para-series: 0.005 and 0.029 , respectively (Table 2 ). When we look at these data by means of canonical structures we find that for para-substituted systems the quinoid form requires the structure with a single charge separation between the donating substituent and the nitro group, whereas for the meta-one a

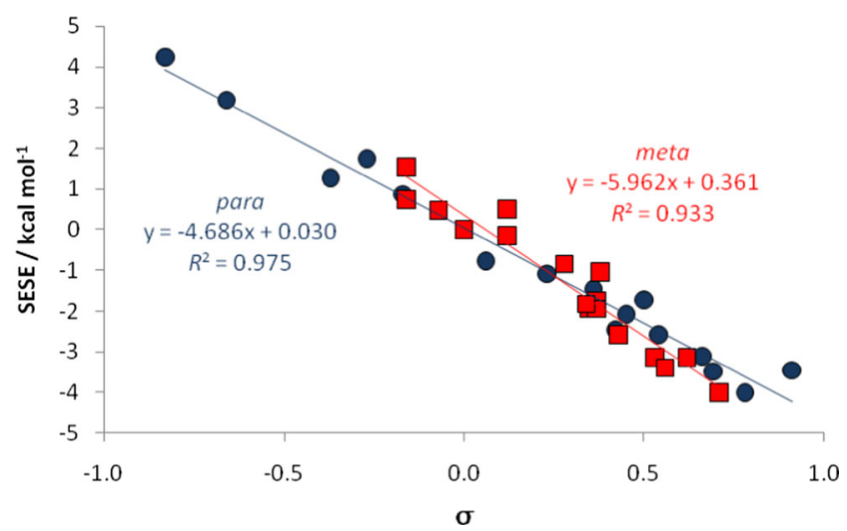

Fig. 2 Regressions SESE $=a \cdot \sigma+b$ for $m e t a$ - and par $a$-series; for a joint set of data: $\mathrm{y}=-4.959 \cdot \mathrm{x}+0.081$ with $R^{2}=0.952$ double excitation is needed, which is energetically much less favorable [35].

The above presented relationship is also observed when $\operatorname{cSAR}(\mathrm{X})$ or SESE are used as SE characteristics. However, for the dependence of $d_{\mathrm{CN}}$ on SESE, shown in Fig. 3, the difference between changeability of $d_{\mathrm{CN}}$ for all meta-derivatives is small, for the para-ones with SESE $<0$ is clearly stronger, whereas the slope for all other points ( $\mathrm{SESE} \geq 0$, the green line in Fig. 3) is much higher and equals to -0.0055 .

This finding is a significant support for the interpretation of the role of the resonance effect on the $\mathrm{CN}$ bond lengths. A similar picture is found when we plot $\operatorname{cSAR}\left(\mathrm{NO}_{2}\right)$ against $\operatorname{cSAR}(\mathrm{X})$ (Fig. S6). The slopes of $\operatorname{cSAR}(\mathrm{Y})$ vs. $\operatorname{cSAR}(\mathrm{X})$ may be used as a measure of an intensity of the communication between $\mathrm{X}$ and $\mathrm{Y}$ [36]. The more negative value the stronger interaction between $\mathrm{X}$ and Y. In Fig. S6 we have three different situations: a very weak interaction for meta-series (the slope $=-0.014)$, in para-series a moderate interaction for EA substituents (the slope $=-0.246$ ) and a very strong interaction for ED substituents with the slope $=-0.755$.

In all presented above cases the regressions for para-series are more precise than for the meta-ones, and almost in all the cases slopes (as absolute values) are greater for para-series.

\section{Substituent effect observed in changes of structural units of $\mathrm{NO}_{2}$ group}

As documented earlier [21], the substituent effect may be observed by mutual correlations between changes of various structural parameters of the reaction site (the $\mathrm{NO}_{2}$ group in the discussed case) and its link to the ring, the $\mathrm{CN}$ bond length. In some cases there are good mutual correlations between these kind of structural parameters. The relation of ONO angle vs. $\mathrm{CN}$ bond length is presented in Fig. S7. Two trends of regression lines are observed. The line for para- substituted systems has a high 
Table 2 Classical model for the description of substituent effects: the equation $f(x)=a \cdot x+b, \Delta$ means the range of $f(\mathrm{x})$ variability; $d_{\mathrm{CN}}$ and $d_{\mathrm{NO}}$ are given in $\AA, \varphi$ in deg and SESE in $\mathrm{kcal} / \mathrm{mol}$

\begin{tabular}{|c|c|c|c|c|c|c|c|c|}
\hline & $f(x)$ & $x$ & $R^{2}$ & $a$ & $b$ & $a_{\mathrm{p}} / a_{\mathrm{m}}$ & $\Delta$ & $\Delta_{\mathrm{p}} / \Delta_{\mathrm{m}}$ \\
\hline & cSAR(NO2) & $\sigma$ & & & & \multirow{3}{*}{4.19} & & \multirow{4}{*}{4.73} \\
\hline$m$ & & & 0.354 & 0.021 & -0.191 & & 0.033 & \\
\hline$p$ & & & 0.943 & 0.090 & -0.221 & & 0.156 & \\
\hline$m+p$ & & & 0.792 & 0.077 & -0.213 & & & \\
\hline & $d_{\mathrm{CN}}$ & $\sigma$ & & & & \multirow{4}{*}{4.71} & & \multirow{4}{*}{5.95} \\
\hline$m$ & & & 0.465 & 0.004 & 1.482 & & 0.005 & \\
\hline$p$ & & & 0.917 & 0.017 & 1.475 & & 0.029 & \\
\hline$m+p$ & & & 0.765 & 0.015 & 1.477 & & & \\
\hline & $d_{\mathrm{NO}}$ & $\sigma$ & & & & \multirow{4}{*}{1.31} & & \multirow{4}{*}{2.48} \\
\hline$m$ & & & 0.910 & -0.003 & 1.225 & & 0.003 & \\
\hline$p$ & & & 0.939 & -0.004 & 1.226 & & 0.008 & \\
\hline$m+p$ & & & 0.903 & -0.004 & 1.225 & & & \\
\hline & $\varphi$ & $\sigma$ & & & & \multirow{4}{*}{0.77} & & \multirow{4}{*}{1.41} \\
\hline$m$ & & & 0.939 & 0.912 & 124.602 & & 0.876 & \\
\hline$p$ & & & 0.966 & 0.702 & 124.625 & & 1.236 & \\
\hline$m+p$ & & & 0.943 & 0.751 & 124.631 & & & \\
\hline & $\operatorname{cSAR}\left(\mathrm{NO}_{2}\right)$ & $\operatorname{cSAR}(\mathrm{X})$ & & & & \multirow{4}{*}{23.16} & & \multirow{4}{*}{4.73} \\
\hline$m$ & & & 0.036 & -0.014 & -0.186 & & 0.033 & \\
\hline$p$ & & & 0.919 & -0.329 & -0.207 & & 0.156 & \\
\hline$m+p$ & & & 0.501 & -0.187 & -0.199 & & & \\
\hline & $d_{\mathrm{CN}}$ & $\operatorname{cSAR}(\mathrm{X})$ & & & & \multirow{4}{*}{12.07} & & \multirow{4}{*}{6.00} \\
\hline$m$ & & & 0.219 & -0.005 & 1.482 & & 0.005 & \\
\hline$p$ & & & 0.885 & -0.062 & 1.477 & & 0.029 & \\
\hline$m+p$ & & & 0.510 & -0.037 & 1.479 & & & \\
\hline & $d_{\mathrm{NO}}$ & $\operatorname{cSAR}(\mathrm{X})$ & & & & \multirow{3}{*}{2.75} & & \multirow{3}{*}{2.48} \\
\hline$m$ & & & 0.618 & 0.006 & 1.224 & & 0.003 & \\
\hline$p$ & & & 0.877 & 0.015 & 1.223 & & 0.008 & \\
\hline$m+p$ & & & 0.683 & 0.011 & 1.224 & \multirow{5}{*}{1.54} & & \multirow{5}{*}{1.41} \\
\hline & $\varphi$ & $\operatorname{cSAR}(X)$ & & & & & & \\
\hline$m$ & & & 0.715 & -1.643 & 124.801 & & 0.876 & \\
\hline$p$ & & & 0.919 & -2.536 & 124.734 & & 1.236 & \\
\hline$m+p$ & & & 0.817 & -2.136 & 124.761 & & & \\
\hline & $\operatorname{cSAR}\left(\mathrm{NO}_{2}\right)$ & SESE & & & & \multirow{3}{*}{5.28} & & \multirow{3}{*}{4.73} \\
\hline$m$ & & & 0.379 & -0.004 & -0.190 & & 0.033 & \\
\hline$p$ & & & 0.945 & -0.019 & -0.220 & & 0.156 & \\
\hline$m+p$ & & & 0.723 & -0.014 & -0.210 & \multirow{5}{*}{5.95} & & \multirow{5}{*}{6.00} \\
\hline & $d_{\mathrm{CN}}$ & SESE & & & & & & \\
\hline$m$ & & & 0.497 & -0.001 & 1.482 & & 0.005 & \\
\hline$p$ & & & 0.928 & -0.004 & 1.475 & & 0.029 & \\
\hline$m+p$ & & & 0.690 & -0.003 & 1.477 & & & \\
\hline & $d_{\mathrm{NO}}$ & SESE & & & & & & \\
\hline$m$ & & & 0.962 & 0.0006 & 1.224 & 1.67 & 0.003 & 2.48 \\
\hline$p$ & & & 0.963 & 0.0009 & 1.225 & & 0.008 & \\
\hline$m+p$ & & & 0.898 & 0.0008 & 1.225 & & & \\
\hline & $\varphi$ & SESE & & & & & & \\
\hline$m$ & & & 0.987 & -0.151 & 124.659 & 0.99 & 0.876 & 1.41 \\
\hline$p$ & & & 0.994 & -0.150 & 124.629 & & 1.236 & \\
\hline$m+p$ & & & 0.990 & -0.151 & 124.644 & & & \\
\hline
\end{tabular}

precision $\left(R^{2}=0.950\right)$ whereas that for the meta ones does not show any correlation $\left(R^{2}=0.489\right)$. While the ranges of $\varphi$ and $d_{\mathrm{CN}}$ values for para-derivatives are large they are more narrow for the meta- ones, particularly for 


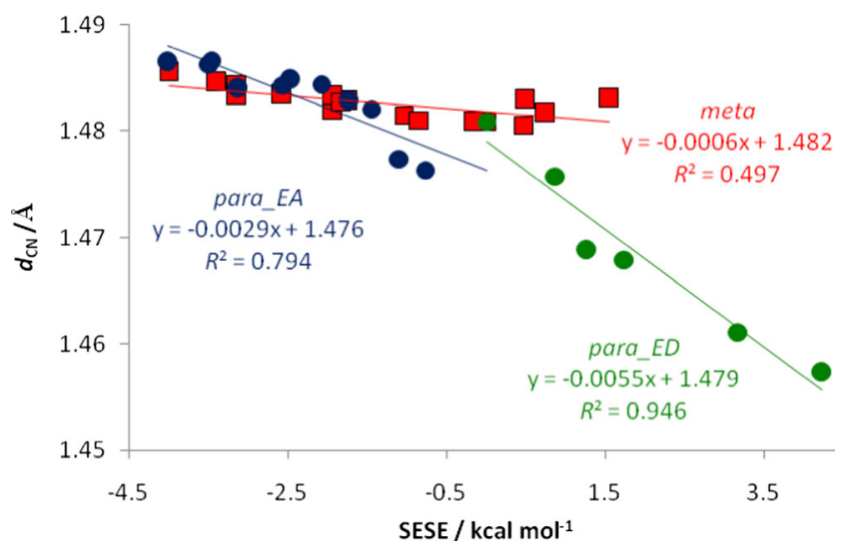

Fig. 3 Regression lines for $d_{\mathrm{CN}}$ plotted against SESE for meta- and paranitrobenzene derivatives. The green regression line illustrates the relation for $\mathrm{ED}$ substituents and $\mathrm{X}=\mathrm{H}(\mathrm{SESE} \geq 0)$

$d_{\mathrm{CN}}$. The latter would suggest a weaker influence of the resonance effect.

The correlation is even better between $d_{\mathrm{NO}}$ and $\varphi$ angle (Fig. S8). For all considered relations (for meta-, para- and the joint data set) $R^{2}$ is greater than 0.920 .

\section{The reverse substituent effect}

As documented recently $[4,21]$, changes in EA/ED properties of a substituent $\mathrm{X}$ in dependence of the kind and nature of the substituted species may be well described by $\operatorname{cSAR}(\mathrm{X})$. Table 3 presents cSAR(X) values for meta- and parasubstituted nitrobenzene derivatives and, for comparison, for monosubstituted benzenes. To show significance of the reverse $\mathrm{SE} \operatorname{cSAR}(\mathrm{X})$ values for nitro and amino groups in appropriate aniline derivatives are added [21] (Table 3, italics).

The most indicative observation is that the difference between $\operatorname{cSAR}(\mathrm{X})$ for meta- and para-values are different for EA substituents and for ED ones. The EA substituents in meta-derivatives have, as a rule, a stronger electron attracting power $(\operatorname{cSAR}(\mathrm{X})$ values are more negative) than the paraones, whereas the ED substituents are stronger donating from para- than from meta-positions. The opposite trends have been documented for aniline series [21], illustrated by values of $\operatorname{cSAR}(\mathrm{X})$ for nitro- and amino-aniline derivatives (Table 3).

Table $3 \mathrm{cSAR}(\mathrm{X})$ values for para- and meta-X-nitrobenzenes as well as for X-benzene (mono) derivatives, and the differences between cSAR(X) for meta- and para-nitrobenzenes as well as for X-nitrobenzene and X-benzene derivatives, $\Delta \mathrm{cSAR}(\mathrm{X})$

\begin{tabular}{|c|c|c|c|c|c|c|c|c|}
\hline $\mathrm{X}$ & $\sigma_{\mathrm{p}}^{\mathrm{a}}$ & $\sigma_{\mathrm{m}}^{\mathrm{a}}$ & para $\mathrm{cSAR}(\mathrm{X})$ & meta $\operatorname{cSAR}(\mathrm{X})$ & mono cSAR(X) & para $\Delta \mathrm{cSAR}(\mathrm{X})$ & meta $\Delta \mathrm{cSAR}(\mathrm{X})$ & $\Delta \mathrm{cSAR}(\mathrm{X})_{\mathrm{m}-\mathrm{p}}$ \\
\hline NO & 0.91 & 0.62 & -0.131 & -0.152 & -0.190 & 0.059 & 0.038 & -0.021 \\
\hline $\mathrm{NO}_{2}$ & 0.78 & 0.71 & $\begin{array}{l}-0.170 \\
-0.284^{\mathrm{b}}\end{array}$ & $\begin{array}{l}-0.168 \\
-0.184^{b}\end{array}$ & -0.202 & $\begin{array}{l}0.032 \\
-0.082\end{array}$ & $\begin{array}{l}0.034 \\
0.018\end{array}$ & $\begin{array}{l}0.002 \\
0.100\end{array}$ \\
\hline $\mathrm{COCl}$ & 0.69 & 0.53 & -0.175 & -0.193 & -0.237 & 0.062 & 0.044 & -0.018 \\
\hline $\mathrm{CN}$ & 0.66 & 0.56 & -0.152 & -0.171 & -0.202 & 0.050 & 0.031 & -0.019 \\
\hline $\mathrm{CF}_{3}$ & 0.54 & 0.43 & -0.112 & -0.129 & -0.154 & 0.042 & 0.025 & -0.017 \\
\hline $\mathrm{COMe}$ & 0.50 & 0.38 & -0.090 & -0.113 & -0.152 & 0.062 & 0.039 & -0.023 \\
\hline $\mathrm{COOH}$ & 0.45 & 0.37 & -0.128 & -0.149 & -0.186 & 0.058 & 0.037 & -0.021 \\
\hline $\mathrm{CHO}$ & 0.42 & 0.35 & -0.114 & -0.136 & -0.172 & 0.058 & 0.036 & -0.022 \\
\hline $\mathrm{CONH}_{2}$ & 0.36 & 0.28 & -0.066 & -0.087 & -0.122 & 0.056 & 0.035 & -0.021 \\
\hline $\mathrm{Cl}$ & 0.23 & 0.37 & 0.016 & -0.010 & -0.036 & 0.052 & 0.026 & -0.026 \\
\hline $\mathrm{F}$ & 0.06 & 0.34 & 0.100 & 0.075 & 0.054 & 0.046 & 0.021 & -0.025 \\
\hline $\mathrm{H}$ & 0.00 & 0.00 & 0.042 & 0.019 & 0.000 & 0.042 & 0.019 & -0.023 \\
\hline $\mathrm{CH}_{3}$ & -0.17 & -0.07 & 0.060 & 0.031 & 0.006 & 0.054 & 0.025 & -0.029 \\
\hline $\mathrm{OMe}$ & -0.27 & 0.12 & 0.168 & 0.126 & 0.102 & 0.066 & 0.024 & -0.042 \\
\hline $\mathrm{OH}$ & -0.37 & 0.12 & 0.162 & 0.129 & 0.105 & 0.057 & 0.024 & -0.033 \\
\hline $\mathrm{NH}_{2}$ & -0.66 & -0.16 & $\begin{array}{c}0.186 \\
0.080^{\mathrm{c}}\end{array}$ & $\begin{array}{l}0.163 \\
0.129^{\mathrm{c}}\end{array}$ & 0.132 & $\begin{array}{l}0.054 \\
-0.052\end{array}$ & $\begin{array}{l}0.031 \\
-0.003\end{array}$ & $\begin{array}{l}-0.023 \\
0.049\end{array}$ \\
\hline $\mathrm{NMe}_{2}$ & -0.83 & -0.16 & 0.219 & 0.163 & 0.137 & 0.082 & 0.026 & -0.056 \\
\hline Average & 0.19 & 0.28 & -0.011 & -0.035 & -0.066 & 0.055 & 0.030 & -0.024 \\
\hline Range & 1.74 & 0.87 & 0.394 & 0.356 & 0.374 & 0.050 & 0.025 & 0.058 \\
\hline Esd & 0.51 & 0.26 & 0.138 & 0.125 & 0.134 & 0.011 & 0.007 & 0.012 \\
\hline
\end{tabular}

${ }^{\text {a }}$ Values substituent constants taken from Ref. [3]

${ }^{\mathrm{b}}$ Values obtained for para- and meta- $\mathrm{NO}_{2}-\mathrm{C}_{6} \mathrm{H}_{4}-\mathrm{NH}_{2}$, respectively, taken from Ref. [21]

${ }^{\mathrm{c}}$ Values obtained for para- and meta- $\mathrm{NH}_{2}-\mathrm{C}_{6} \mathrm{H}_{4}-\mathrm{NH}_{2}$, respectively, taken from Ref. [21] 


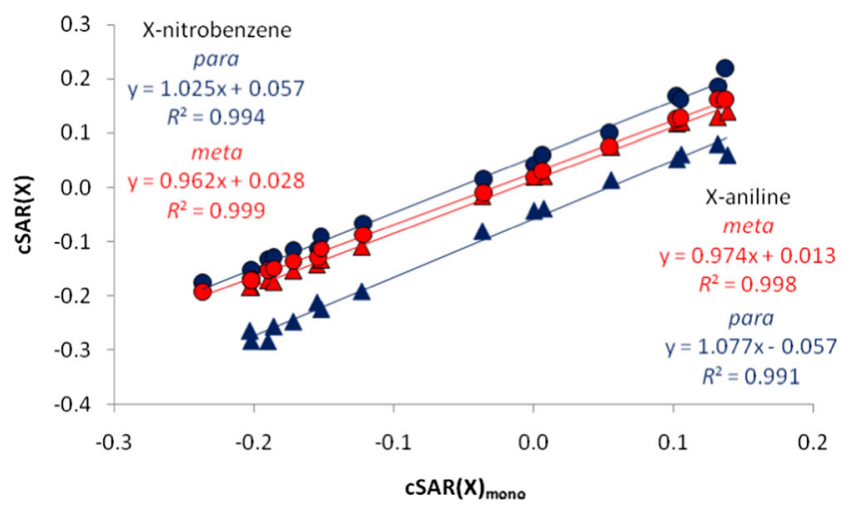

Fig. 4 Relations between $\operatorname{cSAR}(\mathrm{X})$ values for meta- and parasubstituted nitrobenzene and aniline derivatives and $\operatorname{cSAR}(X)$ for monosubstituted benzenes; circles and triangles denote nitrobenzene and aniline systems, respectively; data for aniline systems are taken from Ref. [21]

Let us assume monosubstituted benzene derivatives as a reference system. Then the differences of $\operatorname{cSAR}(\mathrm{X})$ values for di-substituted (X-R-Y) and monosubstituted systems ( $\mathrm{Y}$ $=\mathrm{H}), \Delta \mathrm{cSAR}(\mathrm{X})$, show in a numerical way how far the properties of substituent $X$ may vary depending on the chemical nature of R-Y. These differences both for meta- and paranitrobenzenes are positive. Therefore, the EA substituents characterize weaker attracting power and the ED stronger donating power than found for monosubstituted derivatives. The ranges of $\Delta \mathrm{cSAR}(\mathrm{X})$ variations are for meta-substituted series half of that for the para-ones, similarly as in the case of the ranges of $\sigma_{\mathrm{p}}$ and $\sigma_{\mathrm{m}}$ constants variation.

It can be said that this study is devoted to the nitro group, therefore, let us look at its properties as a substituent. In nitrobenzene systems its EA power decreases, both for para- and meta-positions, by ca. $16 \%$ with respect to the observed in $\mathrm{Ph}$ $\mathrm{NO}_{2}$. When the amino group is the reaction site (aniline derivatives) the EA power of $\mathrm{NO}_{2}$ increases significantly (up to $41 \%$ ) for para-position and decreases (down to $9 \%$ ) for the $m e t a$-one. In nitrobenzene systems the nitro group (the reaction site) strongly affects properties of ED substituents. In the case of the amino substituent - its ED power increases both for para- and meta-positions (by $41 \%$ and $24 \%$, respectively, with respect to the observed in $\mathrm{Ph}-\mathrm{NH}_{2}$ ). The opposite changes of the ED power of $\mathrm{NH}_{2}$ have been found for aniline systems (a decrease by $39 \%$ and $2 \%$, respectively).

The above data present a clear documentation that, the EA/ ED ability of the substituent strongly depend on the character of the reaction site. The application of cSAR parameter allows, in principle, to estimate the reverse SE in a quantitative way for any reaction site chosen. Additionally, a comparison of EA/ED properties of substituents in meta- and parasubstituted nitrobenzene as well as in aniline derivatives in relation to the monosubstituted benzene derivatives is illustrated in Fig. 4. In this case differences in intramolecular interactions for nitrobenzene and aniline substituted derivatives with respect to monosubstituted systems can be discussed.

First, it is important to stress that in all cases correlations are very good with $R^{2}>0.99$. Secondly, presented data illustrate nicely the reverse SE. Finally, as results from the slopes of the presented relationships (Fig. 4) in para-series the intermolecular interaction of substituents with the fixed group $\left(\mathrm{Y}=\mathrm{NO}_{2}\right.$ or $\left.\mathrm{NH}_{2}\right)$ is stronger than in the $\mathrm{Y}=\mathrm{H}$ substituted system, whereas for the meta- ones is oppositely.

\section{Conclusions}

All used characteristics of the SE: the Hammett $\sigma$ constants, $\operatorname{cSAR}(\mathrm{X})$ and SESE are mutually correlated with higher determination coefficients for para-substituted derivatives than for the meta-ones. The best mutual correlation is for SESE $v s . \sigma$ relationships since both characteristics take into account all interactions existing in the substituted systems, whereas $\operatorname{cSAR}(\mathrm{X})$ represent rather local EA/ED properties of the substituent.

Structural characteristics of the nitro group such as ONO angle or NO bond lengths fulfill well dependences between themselves as well as on the SE characteristics. Moreover, only insignificant differences between metaand para-substituted derivatives are observed. Contrary to these, the dependences of $\mathrm{CN}$ bond length on all SE characteristics should be considered separately for ED substituents in para-position due to their much stronger interaction than all other data. This is due to the resonance effect and hence an appearance of the quinoidlike structure.

The reverse substituent effect is confirmed by showing the significant difference between cSAR(X) in para- and metalocated substituents. Comparison with $\operatorname{cSAR}(\mathrm{X})$ for monosubstituted benzene derivatives reveals much stronger electron attraction/donation in para-substituted derivatives than in meta-ones.

In summary, we can state that the application of the cSAR approach allows to estimate ED/EA properties of substituents independently of the system to which the substituent is attached. What is more, this is a handy way to quantify the reverse substituent effect.

Acknowledgements We gratefully acknowledge the Interdisciplinary Center for Mathematical and Computational Modeling (Warsaw, Poland) and Wrocław Centre for Networking and Supercomputing (http://wcss.pl; grant No. 311) for providing computer time and facilities. H.S. and T.M.K. thank the National Science Centre and Ministry of Science and Higher Education of Poland for supporting this work under the grant no. UMO-2013/11/B/ST4/00531. 
Open Access This article is distributed under the terms of the Creative Commons Attribution 4.0 International License (http:// creativecommons.org/licenses/by/4.0/), which permits unrestricted use, distribution, and reproduction in any medium, provided you give appropriate credit to the original author(s) and the source, provide a link to the Creative Commons license, and indicate if changes were made.

\section{References}

1. Campanelli AR, Domenicano A, Ramondo F, Hargittai I (2004) J Phys Chem A 108:4940-4948

2. Exner O, Chapter 10 in Correlation Analysis in Chemistry - Recent Advances, Chapman NB, Shorter J (1978) Eds, Plenum Press New York, 439

3. Hansch C, Leo A, Taft RW (1991) Chem Rev 91:165-195

4. Stasyuk OA, Szatylowicz H, Fonseca Guerra C, Krygowski TM (2015) Struct Chem 26:905-913

5. Charton M (1964) J Org Chem 29:1222-1227

6. Dobrowolski MA, Krygowski TM, Cyrański MK (2009) Croatica Chim Acta 82:139-147

7. $\mathrm{Xu} \mathrm{J}(2012)$ Tetrahedron 68:10696-10747

8. Badgujar DM, Talawar MB, Asthana SN, Mahulikar PP (2008) J Hazard Mater 151:289-305

9. Zhang C (2009) J Hazard Mater 161:21-28

10. Rouchaud J, Neus O, Cools K, Bulcke R (2000) Toxicol Environ Chem 77:31-40

11. Allen FH (2002) Acta Crystallogr sect. B Struct Sci 58:380-388

12. Szatylowicz H, Stasyuk OA, Fonseca Guerra C, Krygowski TM (2016) Crystals 6:29

13. Frisch MJ, Trucks GW, Schlegel HB, Scuseria GE, Robb MA, Cheeseman JR, Scalmani G, Barone V, Mennucci B, Petersson GA, Nakatsuji H, Caricato M, Li X, Hratchian HP, Izmaylov AF, Bloino J, Zheng G, Sonnenberg JL, Hada M, Ehara M, Toyota K, Fukuda R, Hasegawa J, Ishida M, Nakajima T, Honda Y, Kitao O, Nakai H, Vreven T, Montgomery JA, Jr., Peralta JE, Ogliaro F, Bearpark M, Heyd JJ, Brothers E, Kudin KN, Staroverov VN, Kobayashi R, Normand J, Raghavachari K, Rendell A, Burant JC, Iyengar SS, Tomasi J, Cossi M, Rega N, Millam JM, Klene M, Knox JE, Cross JB, Bakken V, Adamo C, Jaramillo J, Gomperts R, Stratmann RE, Yazyev O, Austin AJ, Cammi R, Pomelli C, Ochterski JW, Martin RL, Morokuma K, Zakrzewski VG, Voth
GA, Salvador P, Dannenberg JJ, Dapprich S, Daniels AD, Farkas Ö, Foresman JB, Ortiz JV, Cioslowski J, Fox DJ (2009) Gaussian 09, Revision D.01, Gaussian, Inc., Wallingford CT

14. Fock V (1930) Z Phys 61:126-148

15. Becke AD (1993) J Chem Phys 98:5648-5652

16. Lee C, Yang W, Parr RG (1988) Phys Rev B 37:785-789 16

17. Zhao Y, Truhlar DG (2008) Theor Chem Accounts 120:215-241

18. Head-Gordon M, Pople JA, Frisch MJ (1988) Chem Phys Lett 153: 503-506

19. Ditchfield R, Hehre WJ, Pople JA (1971) J Chem Phys 54:724-728

20. Dunning Jr TH (1989) J Chem Phys 90:1007-1023

21. Szatylowicz H, Siodla T, Stasyuk OA, Krygowski TM (2016) Phys Chem Chem Phys 18:11711-11721

22. Weinhold F, Landis CR (2005) Valency and Bonding. A Natural Bond Orbital Donor-Acceptor Perspective. Cambridge University Press, Cambridge, UK

23. Bader RWF (1990) Atoms in Molecules: A Quantum Theory. Clarendon Press, Oxford UK

24. Hirshfeld FL (1977) Theor Chim Acta 44:129-138

25. NBO 6.0. Glendening ED, Badenhoop JK, Reed AE, Carpenter JE, Bohmann JA, Morales CM, Landis CR, Weinhold F (2013) Theoretical Chemistry Institute, University of Wisconsin, Madison

26. Keith TA, (2013) AIMAll (Version 12.06.03), TK Gristmill Software, Overland Park KS, USA, (aim.tkgristmill.com)

27. Hehre WJ, Ditchfield R, Radom L, Pople JA (1970) J Am Chem Soc 92:4796-4801

28. George P, Trachtman M, Bock CW, Brett AM (1976) J Chem Soc Perkin Trans 2:1222-1227

29. Pross A, Radom L, Taft WR (1980) J Org Chem 45:818-826

30. Hehre WJ, Radom L, Schleyer PvR, Pople JA (1986) Ab Initio Molecular Orbital Theory, John Wiley \& Sons, New York

31. Sadlej-Sosnowska N (2007) Chem Phys Lett 447:192-196

32. Sadlej-Sosnowska N (2007) Polish J Chem 81:1123-1134

33. Krygowski TM, Sadlej-Sosnowska N (2011) Struct Chem 22:1722

34. Hammett LP (1970) Physical Organic Chemistry, McGraw-Hill Book Company, N.Y. chpt. 11, p.333 in Polish Edition, PWN Warszawa, 1976

35. Krygowski TM, Palusiak M, Plonka A, Zachara-Horeglad JE (2007) J Phys Org Chem 20:297-306

36. Siodla T, Oziminski WP, Hoffmann M, Koroniak H, Krygowski TM (2014) J Org Chem 79:7321-7331 